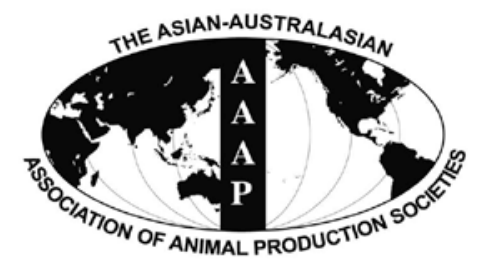

Asian-Aust. J. Anim. Sci.

Vol. 25, No. 2 : 170 - 176

February 2012

www.ajas.info

http://dx.doi.org/10.5713/ajas.2011.11122

\title{
Shallow Population Genetic Structures of Thread-sail Filefish (Stephanolepis cirrhifer) Populations from Korean Coastal Waters
}

\author{
M. Yoon, W. Park, Y. K. Nam and D. S. Kim* \\ Institute of Marine Living Modified Organisms, Pukyong National University, Busan 608-737, Korea
}

\begin{abstract}
Genetic diversities, population genetic structures and demographic histories of the thread-sail filefish Stephanolepis cirrhifer were investigated by nucleotide sequencing of 336 base pairs of the mitochondrial DNA (mtDNA) control region in 111 individuals collected from six populations in Korean coastal waters. A total of 70 haplotypes were defined by 58 variable nucleotide sites. The neighbor-joining tree of the 70 haplotypes was shallow and did not provide evidence of geographical associations. Expansion of $S$. cirrhifer populations began approximate 51,000 to 102,000 years before present, correlating with the period of sea level rise since the late Pleistocene glacial maximum. High levels of haplotype diversities ( $0.974 \pm 0.029$ to $1.000 \pm 0.076)$ and nucleotide diversities (0.014 to 0.019$)$, and low levels of genetic differentiation among populations inferred from pairwise population $F_{\mathrm{ST}}$ values (-0.007 to 0.107), support an expansion of the $S$. cirrhifer population. Hierarchical analysis of molecular variance (AMOVA) revealed weak but significant genetic structures among three groups $\left(F_{\mathrm{CT}}=0.028, \mathrm{p}<0.05\right)$, and no genetic variation within groups $\left(0.53 \% ; F_{\mathrm{SC}}=0.005\right.$, $\mathrm{p}$ $=0.23$ ). These results may help establish appropriate fishery management strategies for stocks of $S$. cirrhifer and related species. (Key Words : Stephanolepis cirrhifer, Mitochondrial Control Region, Demographic History, Population Genetic Structure, Nucleotide Sequence Analysis)
\end{abstract}

\section{INTRODUCTION}

Filefish (family Monacanthidae) include 95 species widely distributed in both temperate and tropical seas (Nelson, 1994). The thread-sail filefish, Stephanolepis cirrhifer (Temminck and Schlegel), is an economically important species for the Korean fishery and aquaculture industries. S. cirrhifer aquaculture has received particular attention because of the fish's high per weight market price and rapid growth rates (market size is reached in only one year) (Miyajima et al., 2011). Although, the species is also widely distributed in the western Pacific Ocean, occurring in the East Sea, the Yellow Sea, and the East China Sea (Masuda et al., 1984; Shao et al., 1990; Nelson, 1994; Ni and Kwok, 1999; Kim et al., 2005) most commercial catches are from the southern coastal area of the Korean Peninsula and the Kuroshio Current of the tropical Pacific Ocean.

In 1985, the $S$. cirrhifer catch in the Northwest Pacific exceeded 250,000 tonnes, but it had decreased to less than

\footnotetext{
* Corresponding Author : D. S. Kim. Tel: +82-51-629-5914, Fax: +82-51-629-5908, E-mail: dongskim@pknu.ac.kr Received April 28, 2011; Accepted June 11, 2011
}

950 tonnes by 2002 (FAO, 2004). Stocks of filefish species are decreasing as a result of overfishing and environmental degradation. Therefore, stock enhancement programs are critically needed to increase severely depleted fishery stocks. Hatchery-based release of filefish is one approach to revitalizing stocks and yields. However, hatchery stocks are susceptible to genetic degradation and reduction of genetic diversity: release of hatchery stocks can threaten the integrity of wild populations by changing the genetic composition and diversity of the gene pool (Allendorf and Ryman, 1987). Thus, evaluation of the biological and genetic characteristics of natural S. cirrhifer populations requires urgent attention to maintain genetic diversity levels and promote sustainable harvests of natural populations.

The primary aim of many historical and evolutionary studies of marine species is to ascertain oceanographic conditions, climatic factors, and vicariant events disrupting gene flow and genetic diversity, in relation to biogeographic patterns of demographic expansion and contraction. Genetic diversity is important for the long-term persistence and survival of natural populations because it confers the ability to adapt to changes in environmental conditions (Frankel and Soulé, 1981). The spatial distributions of population genetic structures are influenced by the effects of gene flow, 
natural selection, genetic drift and mutation (Slatkin, 1987), which may be affected by both current environmental conditions (Weersing and Toonen, 2009) and historical biogeographical processes (Avise, 2000). Assessments of the genetic structure of fish populations can provide invaluable information for successful conservation or management of exploited species (Bailey, 1997; Zang et al., 2006).

Information on nucleotide sequences in maternally inherited mitochondrial DNA (mtDNA) genes is useful for investigating interspecific and intraspecific genetic diversity among closely related taxa, species, or populations (Wilson et al., 1985; Moritz et al., 1987; Avise, 1994). The intraspecific population genetic structures of $S$. cirrhifer population are still poorly understood. A recent study by Yoon et al. (2011) found no differences in the nucleotide sequences of the mtDNA cytochrome $b$ gene (Cyt $b$ ) between $S$. cirrhifer populations off the southern and eastern coasts of the Korean Peninsula. They suggest that substantial gene flow occurs within and between populations of $S$. cirrhifer, and that western Pacific $S$. cirrhifer belong to a single panmictic population; however, this study has not investigated the genetic structure of populations from the west coast of Korea.

In the mtDNA genome, the sequence variability of the non-coding control region is often higher than the variability in coding regions; thus, sequencing of the noncoding region has been recommended for investigating genetic diversity at the intraspecific level (Moritz et al., 1987). Up until now, the mtDNA control region has been generally used to study genetic diversities, population structures, and intraspecific phylogenesis of fish (Brown et al., 1993; Stepien and Faber, 1998; Sato et al., 2001; Guarnieo et al., 2002).

In the present study, we examine the genetic diversity and population structure of $S$. cirrhifer along the Korean coast using sequence analysis of the $5^{\prime}$ end of the mtDNA control region to obtain basic data for fisheries resources management.

\section{MATERIALS AND METHODS}

\section{Sampling and sequencing}

Stephanolepis cirrhifer specimens were collected in 2009 and 2010 from six sites located on three Korean seas: the Yellow Sea (one site), South Sea of Korea (South Sea) (three sites), and East Sea (two sites) (Table 1). All the samples examined, except the Yellow Sea, for the present mtDNA (control region gene) analysis had been used previously for the mtDNA analysis (Yoon et al., 2011). Specimens were stored at $-80^{\circ} \mathrm{C}$ or preserved in ethanol at room temperature until DNA extraction. DNA was extracted from approximately $70 \mathrm{mg}$ of each specimen with a QIAGEN Blood and Cell Culture DNA Midi Kit (Qiagen, Germany) according to the manufacturer's instructions.

The polymerase chain reaction (PCR) was used to amplify the mtDNA control region with the primers StepCR-F (5'-CTAGCTCCCAAGCTAGGATT-3') and StepCR-R (5'-TGGTGAGCCACGTATTGCAA-3'), newly designed on the basis of the complete mitogenomic sequence of $S$. cirrhifer, available in the GenBank genetic sequence data bank (NC_003177). PCR amplification was performed with a DNA Engine thermocycler (MJ Research, Tokyo, Japan) in 20- $\mu$ l reaction tubes containing $100 \mathrm{ng}$ of genomic DNA, $2 \mu \mathrm{M}$ of each primer, $0.25 \mathrm{mM}$ of each dNTP, 1 unit of TaKaRa LA Taq DNA polymerase (Takara Shuzo, Shiga, Japan), and $2 \mu$ of $10 \times$ LA Taq reaction buffer (Takara Shuzo). The PCR conditions consisted of preheating at $94^{\circ} \mathrm{C}$ for $5 \mathrm{~min}$, followed by 35 cycles of $94^{\circ} \mathrm{C}$ for $30 \mathrm{~s}, 58^{\circ} \mathrm{C}$ for $30 \mathrm{~s}$, and $72^{\circ} \mathrm{C}$ for $30 \mathrm{~s}$, with a final 7 min extension at $72^{\circ} \mathrm{C}$.

Table 1. Sampling sites, dates, geographical coordinates, number of individuals examined, and measures of mtDNA diversity in six Stephanolepis cirrhifer populations

\begin{tabular}{|c|c|c|c|c|c|c|c|c|}
\hline \multirow{2}{*}{ Sampling site } & \multirow{2}{*}{ Abbreviation } & \multirow{2}{*}{$\begin{array}{c}\text { Date of } \\
\text { collection }\end{array}$} & \multicolumn{2}{|c|}{ Geographical co-ordinates } & \multirow{2}{*}{$N$} & \multirow{2}{*}{$\begin{array}{c}\text { No. of } \\
\text { haplotypes }\end{array}$} & \multirow{2}{*}{$h$} & \multirow{2}{*}{$\pi$} \\
\hline & & & Latitude & Longitude & & & & \\
\hline \multicolumn{9}{|l|}{ Yellow Sea } \\
\hline Wi-do & WID & Oct. 2010 & $35^{\circ} 35^{\prime} 33.14^{\prime \prime} \mathrm{N}$ & $126^{\circ} 16^{\prime} 23.65^{\prime \prime} \mathrm{E}$ & 7 & 7 & $1.000 \pm 0.076$ & 0.018 \\
\hline \multicolumn{9}{|l|}{ South Sea } \\
\hline Jeju & JEJ & Aug. 2010 & $33^{\circ} 03^{\prime} 14.54 " \mathrm{~N}$ & $126^{\circ} 32^{\prime} 39.67^{\prime \prime} \mathrm{E}$ & 18 & 15 & $0.974 \pm 0.029$ & 0.014 \\
\hline Yeosu & YES & Aug. 2010 & $34^{\circ} 41^{\prime} 22.99^{\prime \prime N}$ & 127³9’59.62"E & 23 & 21 & $0.992 \pm 0.015$ & 0.014 \\
\hline Geoje & GUJ & July. 2010 & $34^{\circ} 43^{\prime} 15.11^{\prime \prime N}$ & $128^{\circ} 41^{\prime} 07.46^{\prime \prime} \mathrm{E}$ & 24 & 18 & $0.967 \pm 0.024$ & 0.015 \\
\hline \multicolumn{9}{|l|}{ East Sea } \\
\hline Pohang & $\mathrm{POH}$ & Oct. 2010 & $36^{\circ} 02^{\prime} 50.30^{\prime \prime} \mathrm{N}$ & $129^{\circ} 24^{\prime} 31.75 " \mathrm{E}$ & 18 & 15 & $0.980 \pm 0.024$ & 0.014 \\
\hline Uljin & ULJ & Oct. 2009 & $36^{\circ} 58^{\prime} 04.20^{\prime \prime} \mathrm{N}$ & $129^{\circ} 26^{\prime} 09.39^{\prime \prime} \mathrm{E}$ & 21 & 18 & $0.986 \pm 0.019$ & 0.019 \\
\hline
\end{tabular}

N: Sample size, $h$ : Haplotype diversity, $\pi$ : Nucleotide diversity. 
The size of the PCR product was verified by $1.0 \%$ agarose gel electrophoresis after ethidium bromide staining. The PCR product was purified with the AccuPrep PCR Purification Kit (Bioneer, Daejeon, Korea). After cycle sequencing with the ABI PRISM BigDye Terminator v3.1 Cycle Sequencing Ready Reaction Kit (Applied Biosystems, Foster City, CA, USA), the purified PCR product was sequenced directly on an ABI 3730xl DNA Analyzer (Applied Biosystems). The primers used for sequencing were the same as those used for PCR amplification.

\section{Data analysis}

The sequence fragments obtained in this study were aligned with GENETIX-WIN ver. 4.0.1 (Software Development Co., Ltd, Tokyo, Japan) to identify sequence variants. The integrated software package DnaSP v. 4.90.1 (Rozas and Rozas, 1997) was used to determine haplotypes. Haplotype diversity $(h)$ and nucleotide diversity $(\pi)$ were estimated according to Nei (1987), based on Kimura's twoparameter distance method, using the $\mathrm{K}$ and $\mathrm{DA}$ in the REAP program (McElroy et al., 1993). Genetic relationships among haplotypes were reconstructed using the neighbor-joining method, generated with the Seqboot, Neighbor, and Consensus options in PHYLIP v. 3.6 (Felsenstein, 1993). A bootstrap analysis of 1,000 replicates evaluated support for phylogenetic relationships after construction of a genetic distance matrix based on nucleotide divergences between haplotypes, estimated according to Nei (1987) and the Kimura two-parameter model (Kimura, 1980).

Pairwise population $F_{\mathrm{ST}}$ values were calculated to estimate genetic differentiation between populations (according to Slatkin, 1991) using ARLEQUIN v. 3.1 (Excoffier et al., 2005). The statistical significance of $F_{\mathrm{ST}}$ values was tested using 10,000 random permutations. The variance component was evaluated at each hierarchical level using analysis of molecular variance (AMOVA) (Excoffier et al., 2005) to assess genetic divergences within and among groups, using ARLEQUIN v. 3.1.

Neutral expectations and historic demographic expansions were investigated by examining Fu's $F_{S}$ and Tajima's $D$ mismatch distributions with the sudden expansion model (Rogers and Harpending, 1992). A goodness-of-fit test was used to test the validity of the sudden expansion model using a parametric bootstrap approach based on the sum of squared deviations (SSD) to compare the observed and the estimated mismatch distributions (Schneider and Excoffier, 1999). Both the neutrality test and the mismatch distribution analysis were performed in ARLEQUIN v. 3.1 (Excoffier et al., 2005).

The mutation rate of the $S$. cirrhifer control region gene over the estimated time since expansion has not been determined. The evolutionary rate for the control region seems to vary among major taxonomic groups of marine fishes. For the Japanese sea bass (Lateolabrax japonicas) and spotted sea bass (Lateolabrax maculates), the sequence divergence rate of the control region is $6 \%$ per million years (Liu et al., 2006). In Nibea albiflora, the sequence divergence rate in the control region is $5 \%$ to $10 \%$ per million years (Han et al., 2008). In the present study, we calculated a sequence divergence rate of $5 \%$ to $10 \%$ per million years for the control region of $S$. cirrhifer.

\section{RESULTS AND DISCUSSION}

\section{Genetic diversity}

Analysis of a 336 base pair fragment of the $5^{\prime}$ - end of the mtDNA control region in 104 individuals of $S$. cirrhifer from six populations defined a total of 70 haplotypes. The neighbor-joining tree of the 70 haplotypes was shallow and did not provide evidence for geographical associations (Figure 1). This suggests a signature of population expansion and/or high gene flow among populations.

Haplotype diversities $(h)$ and nucleotide diversities $(\pi)$ were high for all populations, ranging from $0.974 \pm 0.029$ (JEJ) to $1.000 \pm 0.076$ (WID), and 0.014 (JEJ, YES, POH) to 0.019 (ULJ), respectively (Table 1). Grant and Bowen (1998) suggest four basic scenarios for population demographic histories of marine fishes with different measures of haplotype and nucleotide diversities. They suggest that high haplotype and nucleotide diversities may be attributed to a long evolutionary history in a large population; examples include the Japanese anchovy ( $h=$ $0.91, \pi=0.01)$ and the Atlantic bluefish $(h=0.70, \pi=0.01)$. This condition might also be observed in re-mixed populations of individuals from historically separated populations (Avise, 2000). Therefore, genetic diversity values of $S$. cirrhifer populations might reflect strong dispersal capacities among ancestral populations with a long evolutionary history in Korean waters.

High genetic diversities within and between populations provide a potential genetic resource for future adaptation (Savolainen and Kuittinen, 2000; Hurt and Phillip, 2004). Recent research has examined genetic diversity in other fishes to determine the present status of populations in this area (e.g., Liu et al., 2006; Shui et al., 2009; Xiao et al., 2009).

\section{Population genetic structure}

Estimation of population structures using molecular markers is a powerful approach to understanding the dynamics of natural populations. Pairwise population $F_{\mathrm{ST}}$ estimates are generally low (Table 2), suggesting little genetic differentiation between population pairs, perhaps 


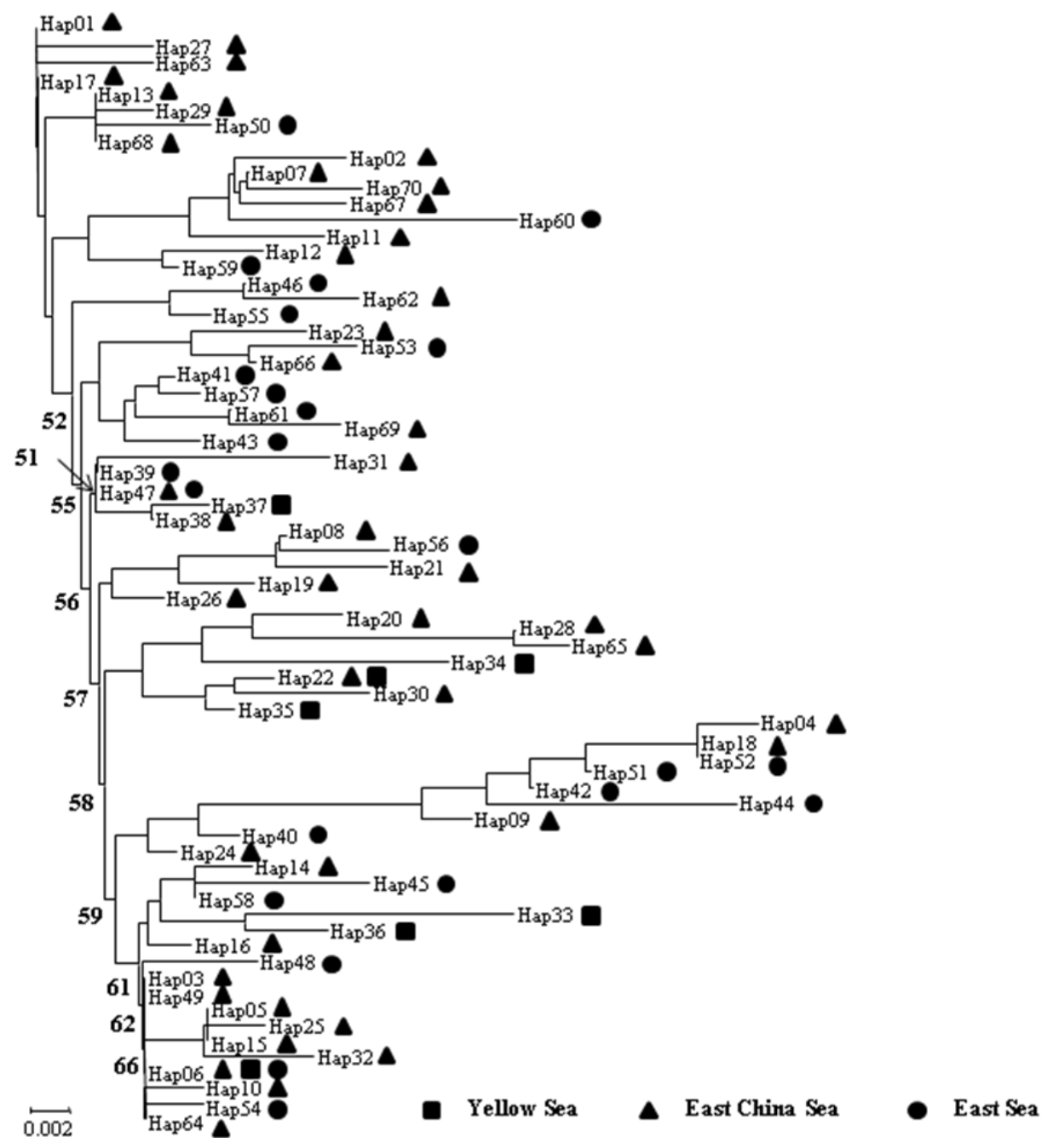

Figure 1. Neighbor-joining tree for 70 control region haplotypes of Stephanolepis cirrhifer. Bootstrap supports of $>50 \%$ in 1,000 replicates are shown.

Table 2. Pairwise $F_{\mathrm{ST}}$ (below diagonal) and p (above diagonal) values among populations of Stephanolepis cirrhifer

\begin{tabular}{lllllll}
\hline Population & WID & JEJ & YES & GUJ & POH & ULJ \\
\hline WID & & 0.05 & 0.01 & 0.02 & 0.01 & 0.01 \\
JEJ & 0.051 & & 0.78 & 0.13 & 0.02 & 0.08 \\
YES & 0.074 & -0.014 & & 0.15 & 0.08 & 0.35 \\
GUJ & 0.103 & 0.020 & 0.016 & & 0.23 & 0.56 \\
POH & 0.107 & 0.043 & 0.027 & 0.011 & & 0.38 \\
ULJ & 0.089 & 0.025 & 0.004 & -0.007 & 0.002 & \\
\hline
\end{tabular}


Table 3. Results of the hierarchical analysis of molecular variance (AMOVA) based on mtDNA control region sequence data for Stephanolepis cirrhifer

\begin{tabular}{|c|c|c|c|c|c|c|}
\hline $\begin{array}{l}\text { Source of } \\
\text { variation }\end{array}$ & $\mathrm{df}$ & $\begin{array}{l}\text { Sum of } \\
\text { squares }\end{array}$ & $\begin{array}{c}\text { Variance } \\
\text { components }\end{array}$ & $\begin{array}{l}\text { Percentage of } \\
\text { variation }\end{array}$ & $F$ index & $\mathrm{p}$ \\
\hline \multicolumn{7}{|c|}{ Analysis 1 . One gene pool } \\
\hline Among populations & 5 & 18.321 & $0.06127 \mathrm{Va}$ & 2.34 & $F_{\mathrm{CT}}=0.02$ & $<0.05$ \\
\hline Within populations & 105 & 267.931 & $2.55172 \mathrm{Vb}$ & 97.66 & & \\
\hline \multicolumn{7}{|c|}{ Analysis 2. Three gene pools (Yellow Sea, South Sea, East Sea) } \\
\hline Among groups & 2 & 9.797 & $0.07311 \mathrm{Va}$ & 2.77 & $F_{\mathrm{CT}}=0.028$ & $<0.05$ \\
\hline Within groups & 3 & 8.524 & $0.01393 \mathrm{Vb}$ & 0.53 & $F_{\mathrm{SC}}=0.005$ & 0.23 \\
\hline Within populations & 105 & 267.931 & $2.55172 \mathrm{Vc}$ & 96.70 & $F_{\mathrm{ST}}=0.033$ & $<0.05$ \\
\hline
\end{tabular}

attributable to high gene flow. High gene flow is characteristic of marine fishes with passively dispersed planktonic larvae and adult migration abilities; their dispersals may be strongly affected by sea currents, and population substructures are limited (Han et al., 2008; Xiao et al., 2009; Kim et al., 2010). The Tsushima Warm Current (TWC) diverges from the Kuroshio Current, with the main flow entering the East Sea west of the Korean Peninsula and a subsidiary flow entering the Yellow Sea (Senjyu, 1999; Ichikawa and Beardsley, 2002). Thus, the TWC may transport larvae into the southern part of the East Sea, near Pohang and Uljin on the Korean coast, and to the Yellow Sea, near Wi-do. Previous studies based on mtDNA Cyt $b$ nucleotide variation have suggested that the South Sea and East Sea S. cirrhifer populations comprise a single population (Yoon et al., 2011). Our mtDNA control region results also showed that estimates of the population differentiation seem to provide similar patterns of genetic differentiation among the South Sea and East Sea populations. However, pairwise population $F_{\mathrm{ST}}$ estimates between Wi-do and all other populations are relatively large (0.051 to 0.107$)$, with significant $p$ values $(<0.05)$, compared to values for all other population pairs $(-0.007$ to 0.043) (Table 2), suggesting that significant population subdivisions exist at small spatial scales.

The genetic structure of $S$. cirrhifer populations around the Korean Peninsula was estimated by AMOVA (Table 3). Overall genetic variation among six populations (Analysis 1 ) was $2.34 \%\left(F_{\mathrm{CT}}=0.02, \mathrm{p}<0.05\right)$, suggesting the possibility of substructures among populations. Analysis of variation within three groups (Yellow Sea, South Sea, and East Sea; Analysis 2) indicated no genetic variation within groups $\left(0.53 \% ; F_{\mathrm{SC}}=0.005, \mathrm{p}=0.23\right), 96.7 \%$ of the total variation due to differences within populations $\left(F_{\mathrm{ST}}=0.033\right.$, $\mathrm{p}<0.05$ ), and $2.77 \%$ of the total variation due to differences among groups $\left(F_{\mathrm{CT}}=0.028, \mathrm{p}<0.05\right)$. The hierarchical pattern of genetic differentiation among groups of $S$. cirrhifer in Korean waters indicates weak but historical patterns of isolation and restriction of gene flow between groups. These results are consistent with previous results based on the mtDNA Cyt $b$ sequence data (Yoon et al., 2011), suggesting that the sequence variability of the mtDNA control region of $S$. cirrhifer could be expected to provide a powerful means with an increased accuracy and resolution to reveal genetic variation as compared with the those of the Cyt $b$ gene. However, differences between the three groups likely arose during isolation into refugia during glacial periods. Rare migrations of strays from the various refugia may have occurred during glaciations. Pleistocene glaciations (2.5 Ma to 10,000 years ago) influenced not only historical demographic patterns (glacial population extinctions and interglacial re-colonizations) but also the demographics of contemporary populations of phylogroups of marine species (Seeb and Crane, 1999; Kitano et al., 2007).

At present, the East Sea is a semi-enclosed marginal sea, which was geographically isolated from the Pacific Ocean during the Pleistocene glacial period (Nishimura, 1974), by a large land bridge that extended from the Yellow Sea to Taiwan (Kimura, 1996, 2000). The present population structure of $S$. cirrhifer populations may represent the influence of this vicariant barrier. Populations of $S$. cirrhifer may have been isolated in the Yellow Sea, the South Sea, and the East Sea during times of glacial maxima.

\section{Historic demography}

Neutral expectations and historical demographic expansions of $S$. cirrhifer were investigated using Fu's $F_{S}$ and Tajima's $D$ tests, and mismatch distributions with the sudden expansion model. Fu's $F_{S}(-25.427 ; \mathrm{p}=0.000)$ and Tajima's $D(-1.708 ; \mathrm{p}=0.020)$ showed significant deviations from the neutral evolution model. The mismatch distributions of $S$. cirrhifer in Korean coastal waters appeared to be unimodal (Figure 2). Significant differences for the sums of the square deviations $\left(\mathrm{p}_{\mathrm{sSD}}<0.05\right)$ between the observed and simulated mismatch distributions indicate that the population is at equilibrium (i.e., a non-expansion phase). The goodness-of-fit test $\left(\mathrm{p}_{\mathrm{sSD}}=0.657\right)$ did not reject the null hypothesis of sudden population expansion for $S$. cirrhifer populations. Thus, both the neutrality tests and the 


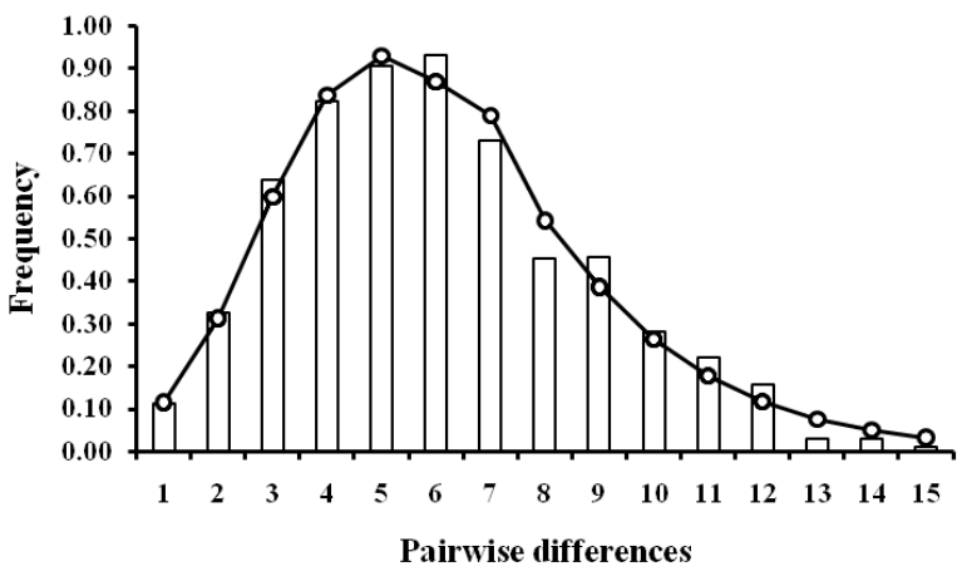

Figure 2. Mismatch distribution constructed using pairwise differences among the mtDNA haplotypes of Stephanolepis cirrhifer. The bars are observed pairwise differences values and the open circles and solid line are the expected mismatch distributions under the sudden expansion model.

mismatch distributions indicate a recent expansion of $S$. cirrhifer populations.

Using $\tau$ (3.436), the expansion was estimated to have occurred 51 to 102 Ma before present, which is consistent with sea level rise since the late Pleistocene glacial maximum. Rising sea level removed barriers to migration and dispersal during the period of postglacial warming, establishing potential gene flow between previously isolated populations. High levels of genetic diversity and low levels of genetic differentiation determined in the present study also support population expansion since the late Pleistocene.

In conclusion, this study found high levels of gene flow among populations of $S$. cirrhifer, weak but significant genetic differentiation of populations on the west coast of Korea (Yellow Sea) and pooled populations in southern and eastern Korean coastal waters. Incorporation of additional population in the Yellow Sea thus provided an increased resolution in the geographic differentiation among three groups of populations. Moreover, the genetic structures of $S$. cirrhifer populations indicate the presence of three geographic population groups (Yellow Sea, South Sea, and East Sea), each of which may require separate fisheries management strategies.

\section{ACKNOWLEDGMENTS}

This work was supported by a research grant (project no. 20088033-1) from the Ministry of Land, Transport, and Maritime Affairs, of the Republic of Korea.

\section{REFERENCES}

Allendorf, F. W. and N. Ryman. 1987. Population genetics and fishery management. In: Genetic Management of Hatchery Stocks (Ed. N. Ryman and F. Utter) University of Washington
Press, Seattle, WA, USA. pp. 141-159.

Avise, J. C. 1994. Molecular markers, natural history and evolution. Chapman \& Hall, New York, USA.

Avise, J. C. 2000. Phylogeography: The History and Formation of Species. Harvard University Press, Cambridge, MA, USA.

Bailey, K. M. 1997. Structural dynamics and ecology of flatfish populations. Neth. J. Sea Res. 37:269-280.

Brown, J. R., A. T. Beckenbach and M. J. Smith. 1993. Intraspecific DNA sequence variation of the mitochondrial control region of white sturgeon (Acipenser transmontanus). Mol. Biol. Evol. 10:326-341.

Excoffier, L., G. Laval and S. Schneider. 2005. Arlequin ver. 3.0: an integrated software package for population genetics data analysis. Evol. Bioinform. 1:47-50.

FAO. 2004. Depleted marine resources: an approach to quantification based on the FAO capture database. FAO Fisheries Circular, No. 1011:18-19. Rome, Fisheries and Aquaculture Organization. Department, Fishery Information, Data and Statistics Unit.

Felsenstein, J. 1993. PHYLIP (Phylogeny Interference Package) Version 3.5c. Department of Genetics, Washington State University, Seattle, USA.

Frankel, O. H. and M. E. Soulé. 1981. Conservation and evolution. Cambridge University Press, New York, USA.

Grant, W. S. and B. W. Bowen. 1998. Shallow population histories in deep evolutionary lineages of marine fishes: insights from sardines and anchovies and lessons for conservation. J. Hered. 89:415-426.

Guarnieo, I., S. Franzellitti, N. Ungaro, S. Tommasini, C. Piccinetti and F. Tinti. 2002. Control region haplotype variation in the central Mediterranean common sole indicates geographical isolation and population structuring in Italian stock. J. Fish Biol. 60:1459-1474.

Han, Z. Q., T. X. Gao, T. Yanagimoto and Y. Sakurai. 2008. Genetic population structure of Nibea albiflora in Yellow Sea and East China Sea. Fish. Sci. 74:544-552.

Hurt, C. and H. Phillip. 2004. Conservation genetics in aquatic species: general approaches and case studies in fishes and spring snails of arid lands. Aquat. Sci. 66:402-413.

Ichikawa, H. and R. C. Beardsley. 2002. The current system in the 
Yellow and East China Seas. J. Oceanog. 58:77-92.

Kim, I. S., Y. Choi, C. L. Lee, Y. J. Lee, B. J. Kim and J. H. Kim. 2005. Illustrated book of Korean fishes. Kyo-Hak Pub Co., Seoul. (in Korean).

Kim, W. J., K. K. Kim, H. S. Han, B. H. Nam, Y. O. Kim, H. J. Kong, J. K. Noh and M. Yoon. 2010. Population structure of the olive flounder (Paralichthys olivaceus) in Korea inferred from microsatellite marker analysis. J. Fish Biol. 76:19581971.

Kimura, M. 1980. A simple method for estimating evolutionary rates of base substitutions that compare studies of nucleotide sequences. J. Mol. Evol. 16:111-120.

Kimura, M. 1996. Quaternary paleogeography of the Ryukyu. Arc. J. Geol. 105:259-285.

Kimura, M. 2000. Paleography of the Ryukyu Islands. Tropics 10:5-24

Kitano, J., S. Mori and C. L. Peichel. 2007. Phenotypic divergence and reproductive isolation between sympatric forms of Japanese threespine sticklebacks. Biol. J. Linn. Soc. 91:671685.

Liu, J. X., T. X. Gao, K. Yokogawa and Y. P. Zhang. 2006. Differential population structuring and demographic history of two closely related fish species, Japanese sea bass (Lateolabrax japonicus) and spotted sea bass (Lateolabrax maculatus) in Northwestern Pacific. Mol. Phylogenet. Evol. 39:799-811.

Masuda, H., K. Amaoka, C. Araga, T. Uyeno and T. Yoshino. 1984. The fishes of the Japanese Archipelago. Tokai University Press, Tokyo, Japan.

McElroy, D., P. Moran, E. Bermingham and I. Kornfield. 1993. REAP: an integrated environment for the manipulation and phylogenetic analysis of restriction data. J. Hered. 83:157-158.

Miyajima, Y., R. Masuda, A. Kurihara, R. Kamata, Y. Yamashita and T. Takeuchi. 2011. Juveniles of thread-sail filefish, Stephanolepis cirrhifer, can survive and grow by feeding on moon jellyfish Aurelia aurita. Fish. Sci. 77:41-48.

Moritz, C., T. W. Dowling and W. M. Brown. 1987. Evolution of animal mitochondrial DNA: relevance for population biology and systematic. Ann. Rev. Ecol. Syst. 18:269-292.

Nei, M. 1987. Molecular evolutionary genetics. Columbia University Press, New York, USA.

Nelson, J. S. 1994. Fishes of the World. 3rd Edn. John Wiley \& Sons Inc., New York, USA.

Ni, I. H. and K. Y. Kwok. 1999. Marine fish fauna in Hong Kong waters. Zool. Stud. 38:130-152.

Nishimura, S. 1974. Formation of the sea of Japan. Tsukiji Shokan, Tokyo, Japan.

Rogers, A. R. and H. Harpending. 1992. Population growth makes waves in the distribution of pairwise genetic differences. Mol. Biol. Evol. 9:552-569.

Rozas, J. and R. Rozas. 1997. DnaSP version 2.0: a novel software package for extensive molecular population genetics analysis. Comput. Appl. Biosci. 13:307-311.
Sato, S., J. Ando, H. Ando, S. Urawa, A. Urano and S. Abe. 2001. Genetic variation among Japanese populations of chum salmon inferred from the nucleotide sequences of the mitochondrial DNA control region. Zoolog. Sci. 18:99-106.

Savolainen, O. and H. Kuittinen. 2000. Small population processes. In: Forest Conservation Genetics: Principles and Practice (Ed. A. Young, D. Boshier and T. Boyle) CABI Publishing, Wallingford, UK. pp. 91-100.

Seeb, L. W. and P. Crane. 1999. Allozymes and mitochondrial DNA discriminate Asian and North American populations of chum salmon in mixed-stock fisheries along the south coast of the Alaska Peninsula. Trans. Am. Fish. Soc. 128:88-103.

Senjyu, T. 1999. The Japan Sea intermediate water; its characteristics and circulation. J. Oceanogr. 55:111-122.

Schneider, S. and L. Excoffier. 1999. Estimation of past demographic parameters from the distribution of pairwise differences when mutation rates vary among sites: application to human mitochondrial DNA. Genetics 152:1079-1089.

Shao, K. T., C. P. Lin, L. T. Ho and P. L. Lin. 1990. Study on the fish communities from northern and southern waters of Taiwan by analyzing the impingement data. J. Fish. Soc. Taiwan 17:73-90.

Slatkin, M. and R. R. Hudson. 1991. Pairwise comparisons of mitochondrial DNA sequences in stable and exponentially growing populations. Genetics 129:555-562.

Stepien, C. A. and J. E. Faber. 1998. Population genetic structure, phylogeography, and spawning philopatry in walleye (Stizostedion vitreum) from mtDNA control region sequences. Mol. Ecol. 7:1757-1769.

Shui, B. N., Z. Q. Han, T. X. Gao, Z. Q. Miao and T. Yanagimoto. 2009. Mitochondrial DNA variation in the East China Sea and Yellow Sea populations of Japanese Spanish mackerel Scomberomorus niphonius. Fish. Sci. 75:593-600.

Weersing, K. and R. J. Toonen. 2009. Population genetics, larval dispersal, and connectivity in marine systems. Mar. Ecol. Prog. Ser. 393:1-12.

Wilson, A. C., R. L. Cann, S. M. Carr, M. George, U. B. Gyllensten, K. Helm-Btchowski, R. G. Higuchi, S. R. Palumbi, E. M. Prager, R. D. Sage and M. Stone-King. 1985. Mitochondrial DNA and two perspectives on evolutionary genetics. Biol. J. Linn. Soc. 26:375-400.

Xiao, Y., Y. Zhang, T. Gao, T. Yanagimoto, M. Yabe and Y. Sakurai. 2009. Genetic diversity in the mtDNA control region and population structure in the small yellow croaker Larimichthys polyactis. Environ. Biol. Fishes 85:303-314.

Yoon, M., J. Y. Jung, Y. K. Nam and D. S. Kim. 2011. Genetic diversity of thread-sail filefish (Stephanolepis cirrhifer) populations in Korean coastal waters inferred from mitochondrial DNA sequence analysis. Fish. Aqua. Sci. 14:1621.

Zhang, J., Z. Cai and L. Huang. 2006. Population genetic structure of crimson snapper Lutjanus erythropterus in East Asia, revealed by analysis of the mitochondrial control region. ICES J. Mar. Sci. 63:693-704. 